\author{
EVS24 \\ Stavanger, Norway, May 13-16, 2009
}

\title{
Living and Mobility - Blue Angel 3 with SAM for a Demonstration Platform of V2G
}

\author{
V. V. Haerri ${ }^{1}$, P. Schweizer ${ }^{2}$ \\ ${ }^{I}$ Center of Competence IIEE, Lucerne University of Applied Sciences \& Arts, Switzerland, vinzenz.haerri@hslu.ch \\ ${ }^{2}$ Center of Competence IIEE, Lucerne University of Applied Sciences \& Arts, Switzerland, paul.schweizer@hslu.ch
}

\begin{abstract}
The development of the Blue-Angel light HEV started already in its $1^{\text {st }}$ generation in 1992. In 2006, the $3^{\text {rd }}$ generation redesign, first as a HEV and later on as a full EV with range extender, was started. The current design-concept is presented in this paper. Emphasis is put on the energy storage integration with a so called $\mathrm{SAM}^{2}$ storage $3^{\text {rd }}$ generation which stands in communication with the energy management of the appropriate building. This paper presents the integration of Blue-Angel in the strategic field of research "living and mobility" of CC IIEE ${ }^{1}$ of the Lucerne University of Applied Sciences and Arts as well as the V2G concept. In this concept, PHEVs and EVs can be utilized for harnessing renewable energy and for providing power for both residential and commercial customers. The amount and the direction of power flow amongst the sub-systems, which include the grid, renewable energy sources, household load and BlueAngel is part of a new management system. The proposed system is an open and universal platform and is expected to gain popularity amongst both commercial and residential users interested in resolving the global energy crisis. The system components will be demonstrated in a show-area platform of the Lucerne University of Applied Sciences and Arts in Horw-Lucerne as well as in a local utility.
\end{abstract}

V2G (vehicle to grid), mobility, BMS (Battery Management System), EDLC (electric double-layer capacitor or supercapacitor), lithium battery

\section{Introduction}

The alarming rate at which global energy reserves are depleting, is a major worldwide concern at economic, environmental, industrial and community levels. A partial solution to this crisis is the use of decentralized generations and vehicle-to-grid (or V2G) plug-in electric vehicles. This paper proposes a 'living and mobility' demonstration system, which has a novel multi-purpose in-house power interface with a plug-in Blue-Angel, which is a light weight plug-in hybrid electric car. The system utilizes Blue Angel hybrid electric vehicle as an energy storage. The storage consists of supercapacitors and Li-Ion batteries. The Integration of the storage system is built with an advanced $\mathrm{SAM}^{2}$ specification concept in its $3^{\text {rd }}$ generation $[10,15]$ and shows high performance concerning supervision, balancing and self check utility. Due to a DC charging-link to the building the proposed system has the flexibility for the integration of multiple renewable sources, and is expected to be easily adapted to micro-grid environments. This concept is gaining more and more popularity as the vehicle has now become an indispensible component in both 'living and mobility'.

Blue-Angel shall be showed together with a small low energy showroom building. With this platform different aspects of research and demonstration can be shown. In this combination, the project is unique in Switzerland and Europe. Important projects for further V2G aspects are going on. 


\section{History and Background}

During the last 15 years CC IIEE $^{1}$ has accomplished a lot of projects with batteries and supercapacitors such as e.g. the small hybrid vehicle Blue-Angel with a first generation $\mathrm{SAM}^{2}$ or elevators $[1,2,3,9]$.

In April 1997, the performance of supercapacitors was demonstrated when the light hybrid vehicle Blue-Angel pulled an eighty tons heavy engine "Lok 2000" of the Swiss Federal Railway Company several meters away (Fig.1). With this event the technical and economic potential of this new energy storage could be shown.

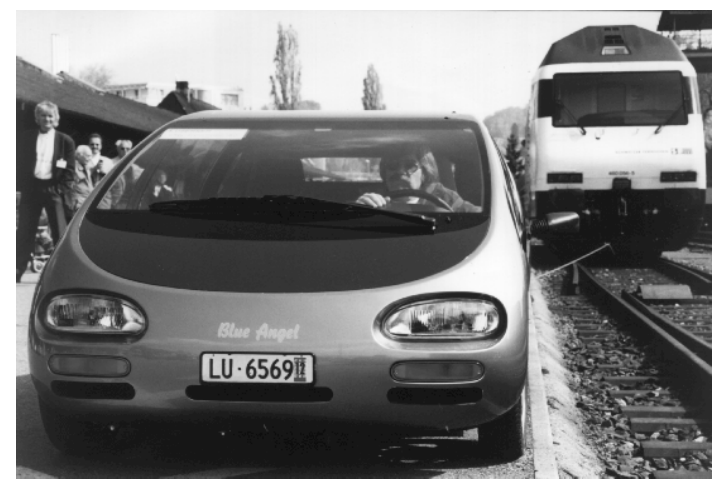

Figure 1: Blue-Angel pulls a Lok 2000

Since June 1997 the research and development activities led to the projects $\mathrm{SAM}^{2}$ and TOHYCO-Rider ${ }^{3}$. The main topics treated in these projects are the integration of energy storages including the use of an adequate management system, which communicates by means of a bus system (e.g. CAN-bus). Also the modeling of batteries and supercapacitors for simulations and demonstration of prototypes are important issues.

The TOHYCO-Rider bus concept consisted of a serial hybrid drive, the supercapacitor energy storage of $1.5 \mathrm{kWh}$ and the fast charging station $\mathrm{IPT}^{4}$. The basic principle is the fast recharging of the bus at every bus stop by the IPT charging

${ }^{1}$ CC IIEE: Center of Competence "Integrated, Intelligent and Efficient Energy Systems", research institute of Lucerne university of Apllied Sciences and Arts; several participations at the EVSs $[2,3,9]$

${ }^{2}$ SAM: Super Accumulator Module, the integration technology of CC IIEE, consisting of batteries, supercaps and its management; name and concept by CC IIEE.

${ }_{3}$ TOHYCO: Total Hybrid Concept for an Ultra Low Emission and Consumption hybrid or electric car using SAM.

${ }^{4}$ IPT: Inductive Power Transfer station. For short rides without IPT an additional and emergency traction battery (ZEBRA, $\mathrm{NaNiCl}$ ) is integrated. Another very important part is the complete control by an energy management system (CAN-Bus-system).

In 2004, the pilot service between the railway and ship station of Lucerne (Fig. 2) and the "Swiss Museum of Transport and Communication" took place. At both bus stops IPT charging stations were installed. The energy of $1.5 \mathrm{kWh}$ was charged in about 3 minutes and was sufficient for the $3 \mathrm{~km}$ ride. Overall, the test period was very satisfactory and gave evidence of the correct function of the system.

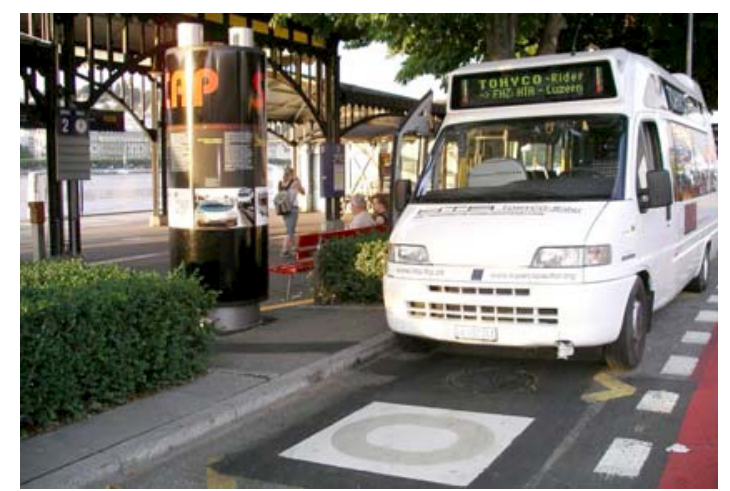

Figure 2: Bus stop of the TOHYCO-Rider at the railway station in front of peer 2 of the "Lake Lucerne Ship Company": the bus stop is shown with an oversized SCAP including project documentation. In front of the bus the IPT charging island can be seen

In 2006, the TOHYCO-Rider bus served as a demonstrator in the "Swiss Museum of Transport and Communication". In a demonstration drive from the museum out on a main road and back into the museum, visitors could take a ride and got familiar with the hybrid technology of the supercapacitor bus. During this time extensive measurements showed an overall specific energy consumption value of about $88 \mathrm{Wh} / \mathrm{t} \cdot \mathrm{km}$ as well as an energy saving of about $12-15 \%$ for a hard "stop and go" ride due to the energy regeneration with the $\mathrm{SAM}^{2}$ storages [4].

Today batteries and supercapacitors are even more important components for electric and hybrid cars, busses, generally for electric drive systems but also for energy buffers in buildings. Since 2006, CC IIEE is therefore working on a strategy called "living \& mobility" which means all types of interactions between the mobility demand and efficient building solutions (building energy saving, decentral power supply, intelligent energy storages, and so on) [14]. 


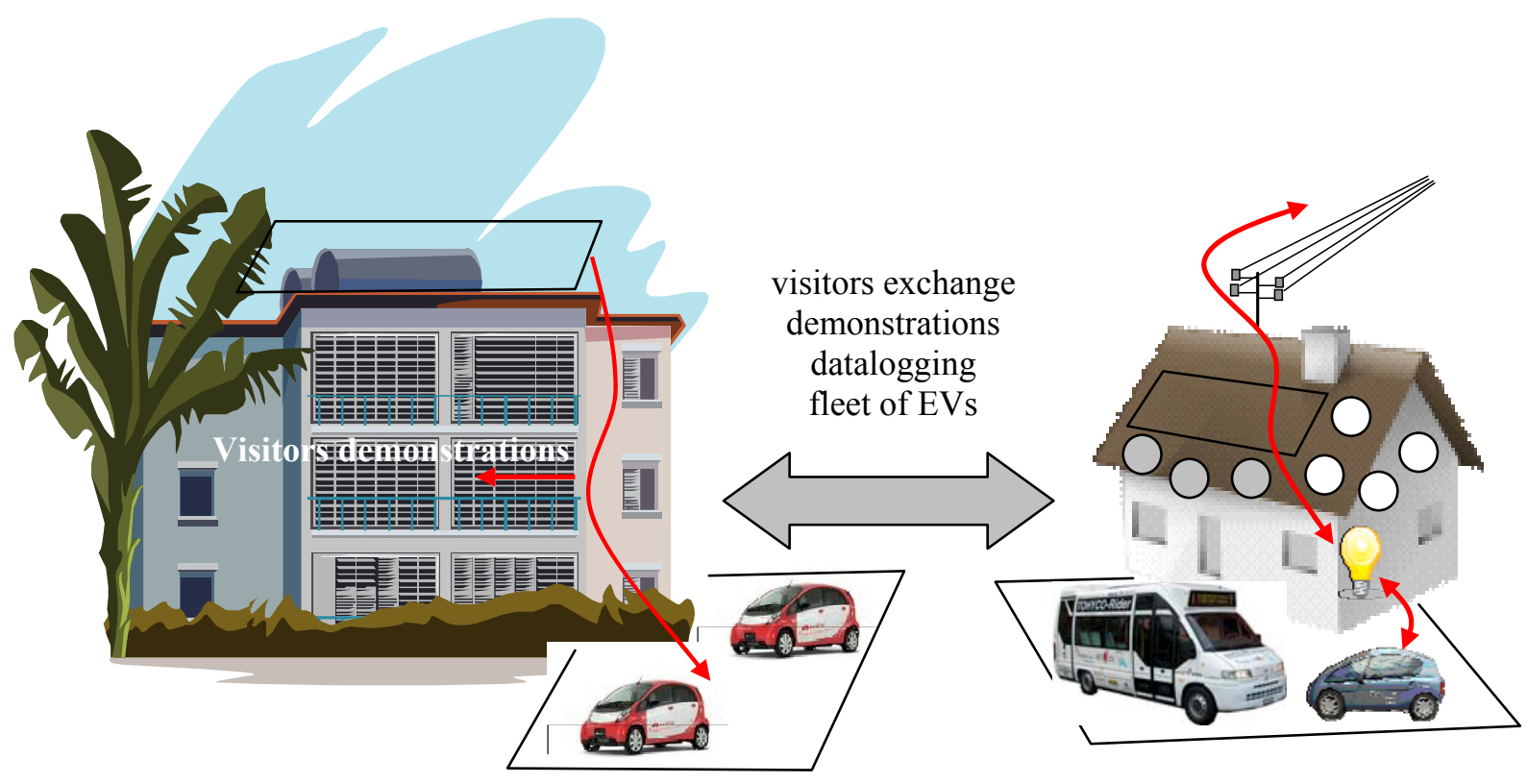

Figure 3: research and demonstration platforms with white bullets as sources, grey bullets as drains and icon "bulp" as management

\section{Research Strategy}

The research strategy "living \& mobility" of CC IIEE $^{1}$ will be demonstrated in a open systemplatform of two showrooms, one in Horw near Lucerne at the university and the other planned at a local utility ${ }^{5}$ (Fig.3).

The demonstration platform as the main part of the complete research system consists of components (second part) and the infrastructure aspects (third part) as shown in Fig.4:

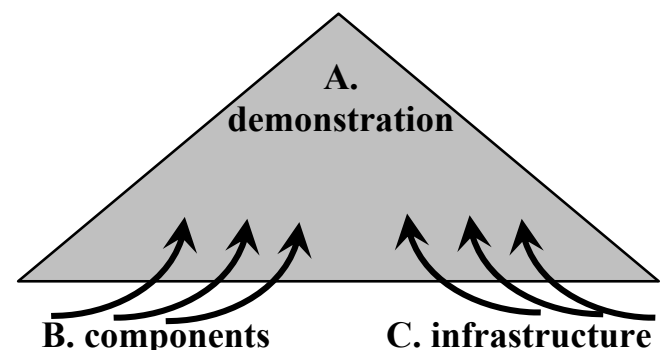

Figure 4: The three main areas of research work tested and demonstrated. Some vehicles have to be evaluated and integrated into the houses and its power management. Basic questions of the mobility use shall be treated too.

B. Components: Basic work on components for A. have to be done, such as the integration of energy storages (in our case LiFePO and supercaps) with balancing circuitries and the development of complete modules $\left(\mathrm{SAM}^{2}\right)$, bidirectional chargers and communication hard- and software.

C. Infrastructure: This point means all aspects of intelligent integration of components for the use of house-management, smart grids and in a later stage of V2G. Intelligent algorithms, energy-flow regulations and an intelligent communication have to be pointed out here.

A. Demonstration: The demonstration platform serves for the dissemination of experiences and applications. In the showrooms all current and future experiences and system relations shall be 


\section{Research Topics}

The above mentioned three fields of research are structured into several smaller projects which are treated in close cooperation with different research partners. The planned topics are shown in table 1.

Table1: Topics in the three fields of research

\begin{tabular}{|c|c|c|}
\hline A) demonstration & B) components & C) infrastructure \\
\hline showroom Horw & $\begin{array}{l}\text { battery and } \\
\text { supercap modelling }\end{array}$ & $\begin{array}{l}\text { preparing } \\
\text { showroom Horw }\end{array}$ \\
\hline visitor showroom & energy storage & \\
\hline Utility $^{5}$ & LiFePO & $\begin{array}{l}\text { decentral energy } \\
\text { supplies) }\end{array}$ \\
\hline power-plant & charging & energy \\
\hline "house" (various & infrastructure: & management \\
\hline $\begin{array}{l}\text { decentral energy } \\
\text { supplies) }\end{array}$ & $\begin{array}{l}\text { normal, fast, DC, } \\
\text { IPT (inductive) }\end{array}$ & "house" \\
\hline $\begin{array}{l}\text { Blue-Angel as EV } \\
\text { with "range- } \\
\text { extender" }\end{array}$ & $\begin{array}{l}\text { communication } \\
\text { hardware for } \\
\text { management: } \\
\text { vehicle, building, } \\
\text { grid... }\end{array}$ & $\begin{array}{l}\text { communication } \\
\text { strategies for } \\
\text { management and } \\
\text { services }\end{array}$ \\
\hline $\begin{array}{l}\text { CKW fleet of EVs } \\
\text { scope of basic } \\
\text { mobility concepts }\end{array}$ & & $\begin{array}{l}\text { V2G strategies } \\
\text { grid simulation }\end{array}$ \\
\hline
\end{tabular}

\section{Results}

A lot of the topics in table 1 are going to be established as projects soon, others are current projects and some of them are traditionally treated at CC IIEE already for a longer period of time.

In this chapter we will present the three highlighted subprojects in table 1, the energy storage $\mathrm{SAM}^{2}$ (components), Blue-Angel as EV with range-extender (demonstration) and $\mathrm{V} 2 \mathrm{G}$ strategies (infrastructure), which is currently a very well known and important matter worldwide.

\subsection{Energy Storage SAM}

The basic concept of $\mathrm{SAM}^{2}$ is shown in Fig.5. It consists of a combination of batteries (in our case mainly LiFePO or ZEBRA), supercapacitors and intelligence which communicates with applications, e.g. the energy management of a house.

But SAM also includes a development methodology from simulation to the energy

5 It is planned to be CKW (means "Centralschweizerische Kraftwerke"), the major power plant of the region Lucerne. A possible cooperation is in discussion. management algorithm and further on to the production of commercial packages.

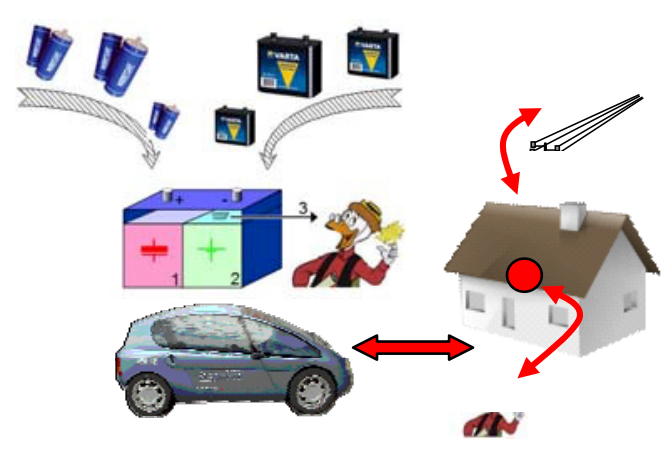

Figure 5: The basic concept of SAM, a combination of supercapacitors (1), battery (2), and intelligence (3), including simulation and production strategies as well as a communication interface for the management of the building and later on of the grid (V2G).

An integrated module like SAM has to fulfill at least the following basic specifications:

- overvoltages have to be avoided

- charge balancing circuit as well as temperature control have to be installed for serial combination of energy storages $[1,5,9]$

- the power dissipation has to be under control and may be ventilated away

- the voltage has to be transferred to the DC-link voltage

- the behavior of the module stack has to be communicated to the superior application control

- the cost structure has to be optimized

All the mentioned points above have already been realized in the first and second generation SAM (Blue-Angel hybrid car in 1997 and TOHYCORider bus in 2006). The current second generation SAM, in this case only consisting of supercaps, is shown without packaging in Fig. 6 [6].

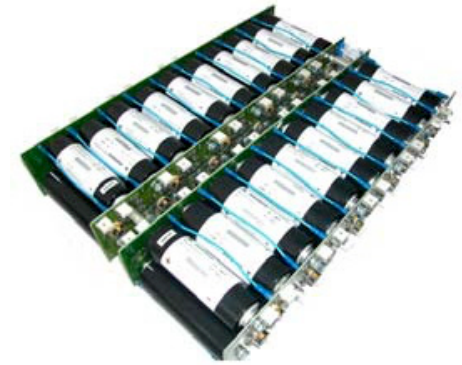

Figure 6: 2nd generation SAM with 40 SCAPs: the multilayer PCB contains the main current conductors, the patented balancing circuitry VP (virtual parallel circuit), supervision as well as a CAN-bus interface 
For universal SAM with a great market potential the advanced specification for a third generation SAM can be defined by the following additional points [11]:

- for a stack consisting of many supercapacitors the balancing circuit has to be equipped with a very good self check utility which also allows to detect $\mathrm{SoH}$ (state of health)

- the SAM should be combined and connected together very easily by a special plug,

- every single SAM should be easily exchangeable for maintenance reasons,

- the SAMs should be able to communicate with the most popular communication systems, such as CAN-bus or others,

- in the same way a combination with different types of power converters should be possible,

- the packs should be combined to SAMs with specific sizes according to customers wishes and

- SAMs should of course comply with the relevant standards, especially for EMC.

A very important issue is the design of the balancing circuits. A lot of work has already been done in this area by CC $\operatorname{IIEE}^{1}[1,3,5,10]$. Currently the industrialization of the $3^{\text {rd }}$ generation SAM is taking place [13].

The management of energy storages is of great importance. SAMs cannot be considered to be isolated elements. They are only parts of several sources and drains. For the energy fluxes of a whole drive system like e.g. hybrid bus or an EV the SAMs must therefore interact with other system elements. The way this is done is called energy management. SAM's own intelligence has to guarantee safe operation of the module as well as long life (minimizing the cost) of the module. Part of this can be realized in a decentral intelligence in the SAMs itself. If a vehicle is coupled to a building, then according to the V2G concept this management has to communicate with the energy management of a decentral supplied building or even with a superior regulation of the grid.

Therefore, we consider the energy storage management not as an isolated intelligence but rather as an open system.

\subsection{Blue-Angel HEV}

Blue-Angel III, shown in Fig.7 a), is a hybrid electric vehicle, which runs on a supercapacitorbattery energy buffer $\mathrm{SAM}^{2}$, shown in Fig.7 b) and c). It is a Plug-In hybrid vehicle with add-on range extender.

Specification of Blue-Angel III:

- Plug-In with add-on Range Extender

- Length/Width/Height: 280 x 144 x $120 \mathrm{~cm}$

- Curb Weight: $500 \mathrm{~kg}$

- Seating Capacity: 2

- Battery capacity: $15.4 \mathrm{kWh}$

- Electric Range: $210 \mathrm{~km}$ (ECE cycle)

- Range with Extender: $530 \mathrm{~km}$ ( $\approx 25 \mathrm{kWhel}$ from

Range Extender)

- Max. power, drive train: $35 \mathrm{~kW}$

- On-board fast charger: $11 \mathrm{~kW}$

- Fast Charge capability: $35 \mathrm{~km}$ in 15 minutes

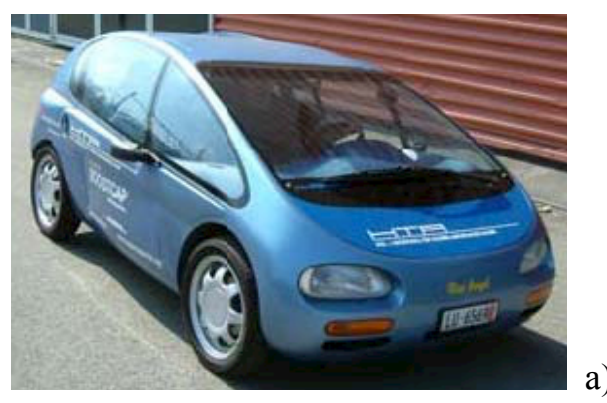

a)

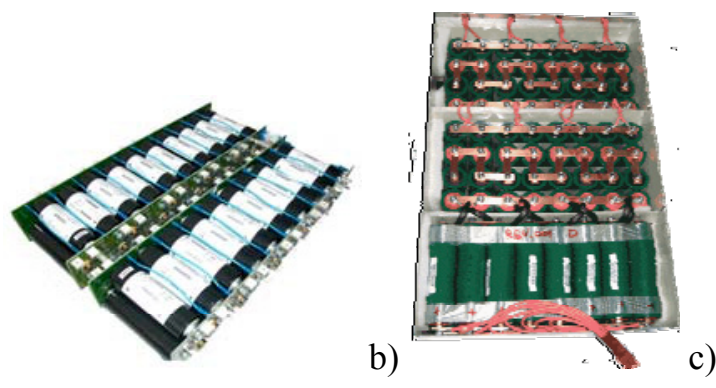

Figure 7: Plug-in-hybrid Blue-Angel a) and parts of module SAM (Supercaps b) and LiFePO c))

The energy buffer SAM of the Blue-Angel is made out of a high energy battery (Li-Ion) and high power supercapacitors, and is controlled by the SAM's intelligence. The Blue-Angel car is an ultra-light vehicle with two seats, and is less than half the weight of a comparable production car and has the following features: 
- much larger storage capacity than a pure hybrid drive. Most of the rides shall be done on electric drive only. An electric driving range of more than $200 \mathrm{~km}$ shall be reached.

- batteries with a low power density can be supported by a supercapacitor module

- the limited electric range can be extended with a light weight range extender, which is mounted in the car according to the driving needs

- empty weight with SAM: only $500 \mathrm{~kg}$ !

- SAM-module (battery plus SCAPs) including energy management with a maximum of $180 \mathrm{~kg}$

- drive train with a maximum power of $35 \mathrm{~kW}$ to provide decent acceleration to the top speed of $120 \mathrm{~km} / \mathrm{h}$ (limited by motor controller)

- range extender with power to provide average power for long highway drives. To be mounted in the car only when needed.

- power connector to building with high DC current capabilities for fast charge/discharge

- an interface for the user to interact with decentralized generation, energy supplier

- powerline or wireless communication interface.

\subsection{V2G Strategies}

\subsubsection{Basic Idea}

A conceptual schematic of the proposed 'living and mobility' system is shown in Fig.8. The system is constructed using a modular based approach to enable integration of four primary sub-systems, when necessary, with ease. As shown in Fig.8, these primary sub-systems constitute different types of renewable energy sources, the Blue Angel hybrid vehicle, the utility grid and the residential load. Solid arrows in Fig.8 represent the direction of power flow while other arrows depict the communication between sub-systems. A power interface, with an optional hybrid energy buffer, is employed in the system as the main hub, to which all these subsystems can easily be integrated through a common DC bus.

Both amount and direction of power exchange amongst the sub-systems are controlled via a power interface module by an efficient energy management unit in accordance with the system variables, which include future and current power demand, spot electricity pricing, available energy storage and renewable generation, amount of spinning reserves, carbon foot print, etc. Communication between sub-systems and utility supplier and/or system control can be wired or wireless. More information is to be found in $[7,8,10,12,15]$.

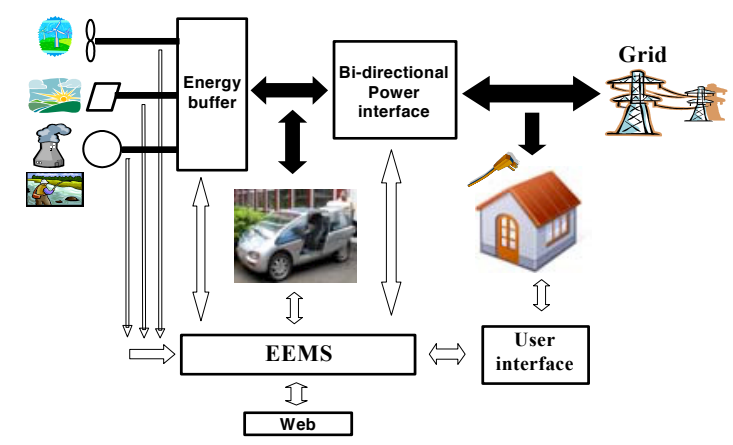

Figure 8: A schematic of 'living \& mobility' concept

\subsubsection{Function Principle of V2G}

The effectiveness of the proposed concept was investigated through simulations using recorded data. A photovoltaic (PV) system was considered as the only energy source while the batteries in Blue-Angel (BA) and a stationary battery in an office were considered as storage elements. The simulations were carried out according to the following specifications and assumptions.

Blue-Angel (BA) is used as the commuting vehicle to and from an office in the morning and in the evening. The journeys are $33 \mathrm{~km}$ each way, uphill in the morning and downhill in the evening. The office is supplied by a PV plant that has peak power capacity of $2.8 \mathrm{~kW}$ to power two computer workstations, lighting, a coffee machine and a microwave oven during lunch time. The battery of BA is used as the V2G power when required, and also supplements a stationary battery in the office, which has less capacity. Any surplus PV power is used to charge the battery of BA first, if parked in the office site, and this is followed by charging the office battery and supplying power to grid or PV2G.

Simulations were performed for three different weather conditions given below:

1. sunny autumn day

2. partially clouded autumn day

3. sunny winter day

Under each weather condition, the PV power was utilized according to the following three criterions. 
1. "state of the art":

$\mathrm{PV}$ power is fed to grid/office via inverter.

Blue Angel battery is charged from grid at office/home with built in charger

2. "integrated energy management - V2G" according to the following priorities:

a. As long as PV power is more than office load, first the battery of BA is charged and after that the office battery (OB) is charged.

b. When PV power is not sufficient, office load is first powered by office battery and after that $\mathrm{BA}$ is providing power (V2G)

3. Like b), but without office battery (OB)

The energy consumption and state of battery charge (SOC) in simulated results, shown below, can be interpreted by using the following legend.

1 Office load supplied by Office Battery (OB)

2 Journey of Blue Angel

3 Office load supplied by BA Battery (V2G)

4 Office Load

5 PV to Battery of Blue Angel

6 PV to Office Battery

7 PV to Grid

8 Blue Angel charged from grid

9 Clouds reducing PV power

10 Office supplied by grid

Out of possible nine combinations above, simulated results are presented only for two combinations: 1a) in Fig.9 and 1b) in Fig.10.

The following assumptions have been made for both simulations 1a) and 1b):

- Energy produced by PV 17'120 Wh

- Energy consume by BA 4'636 Wh

- Energy consumed by Office 3'210 Wh

- energy BA to Office (V2G) $0 \mathrm{Wh}$

- BA battery capacity $\quad 15400.00 \mathrm{Wh}$

- BO battery capacity $\quad 4000.00 \mathrm{Wh}$

- peak power PV $2800.00 \mathrm{~W}$

- average power BA $\quad 4950.00 \mathrm{~W}$

- average power BA downhill $2000.00 \mathrm{~W}$

- SOC max to batt BA $95 \%$

- SOC maximum to BO $91 \%$

- efficiency inverter to grid $\quad 91 \%$

- efficiency charger $\quad 85 \%$

- efficiency battery $\quad 84 \%$

- efficiency DC-DC $\quad 96 \%$

- efficiency DC-AC V2G $\quad 93 \%$
The following values are shown in Fig.9 for energy consumption and distribution of 1a):

- Energy BO to Office $0 \mathrm{Wh}$

- Energy PV to BA $0 \mathrm{Wh}$

- Energy PV to BO $0 \mathrm{Wh}$

- Energy PV to grid $12^{\prime} 419 \mathrm{Wh}$

- Energy grid to BA (charge) 6'667 Wh

- Energy to/from grid (+/-) 5'752 Wh

This is achieved with the following parameters:

- SOC min to grid BA $\quad 95 \%$

- SOC minimum to grid BO $\quad 91 \%$

The following values are shown in Fig.10 for energy consumption and distribution of $1 \mathrm{~b}$ ):

- Energy BO to Office

$194 \mathrm{Wh}$

- Energy PV to BA

$3476 \mathrm{Wh}$

- Energy PV to BO

$204 \mathrm{Wh}$

- Energy PV to grid

8 '552 Wh

- Energy grid to BA (charge) 1'961 Wh

- Energy to/from grid (+/-) 6’291 Wh

This is achieved with the following parameters:

- SOC min to grid BA

$40 \%$

- SOC minimum to grid BO

$25 \%$

\subsubsection{Discussion}

The simulations 1a) and 1b) in Fig.9 and 10 "state of the art" versus "integrated energy management V2G" can be discussed as follows:

With integrated energy management- V2G the following changes can be observed:

- At same PV production, energy balance at grid has increased by $539 \mathrm{Wh}: 3.1 \%$ increase of PV to grid production

- Better "local load levelling": 8'552 Wh compared to $12^{\prime} 419 \mathrm{Wh}$ to grid - 1'961Wh compared to 6'667Wh from grid

- short charge time of BA of less than 1 hour compared to 3 hours. Charge time could easily be shifted during night time

- SOCmin (Minimum State of Charge) of battery BA $73.5 \%$ compared to $64.9 \%$ in 1a). This will lead to an increase of battery life. Since delta SOC is only about $25 \%$, such cycles are almost considered as micro cycles. A cycle life of more than $8^{\prime} 000$ of such $25 \%$ cycles is expected. 
Energy Management: PV plant, Office load, Blue Angel, V2G

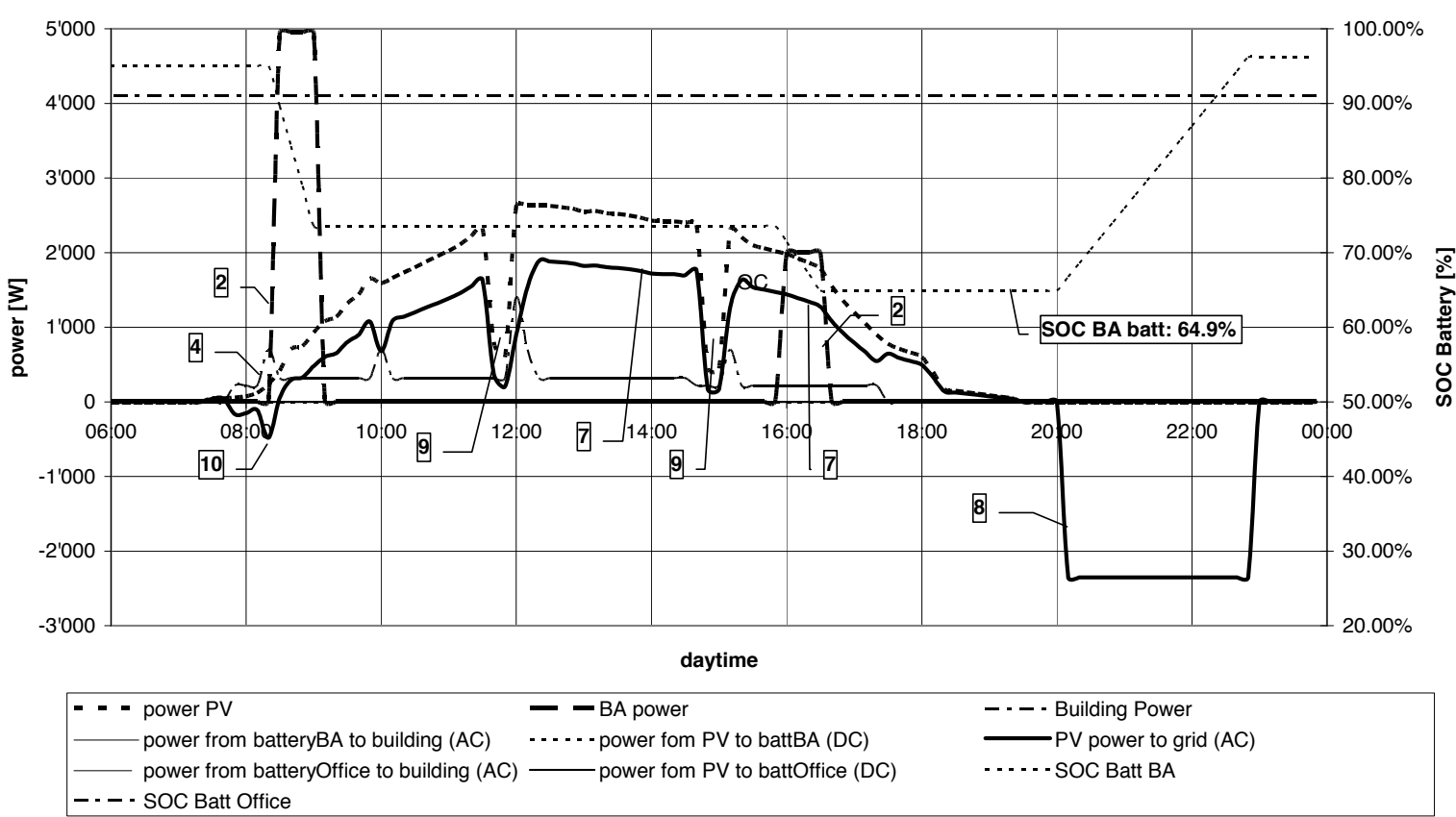

Figure 9: Power and SOC variation over a day for condition 1a)

Energy Management: PV plant, Office load, Blue Angel, V2G

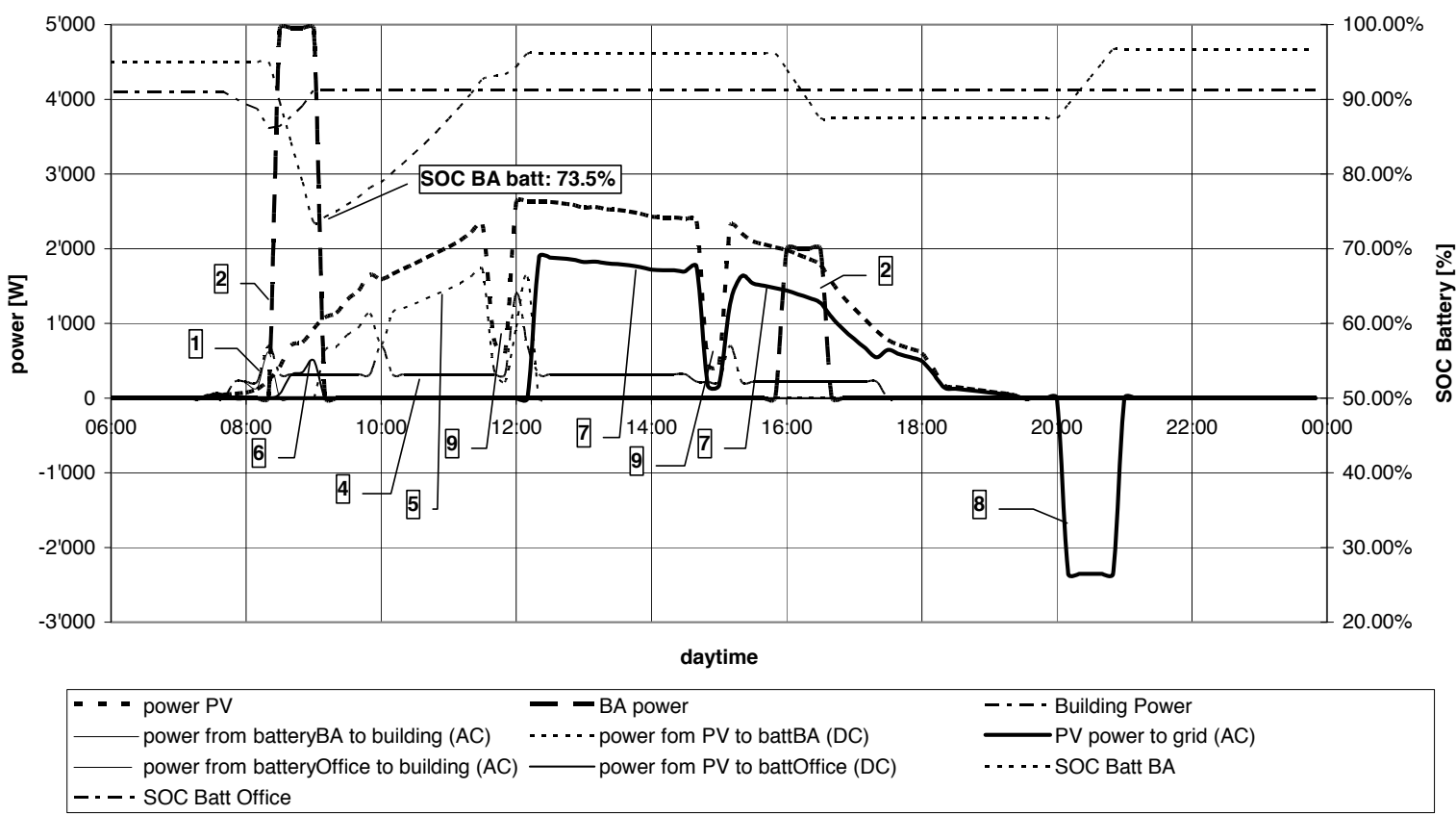

Figure 10: Power and SOC variation over a day for condition 1b) 


\section{Conclusion}

The new PHEV design of the Blue-Angel III with range-extender includes hybrid vehicle management experiences for over 10 years. The most important component is an energy storage system on a high systemic integration level, so called SAM, which is able to communicate intelligently with a higher level management in a building and later on for V2G. Beyond that, V2G strategies are explored with Blue-Angel III and show that the $V 2 \mathrm{G}$ concept is of great importance. The common objective of all research activities at the CC IIEE is a demonstration system consisting of different show-rooms with decentral power generation, serving as platform for testing research results and for visitor demonstrations.

\section{References}

[1] V. Härri, P.Erni, S.Egger, P.Schweizer: Anwendungspotential von Superkapazitätenspeichern SAM, PSEL Studie154 of the Project Fund of Swiss Electricity Economy, update version of March 2001, www.hslu.ch/iiee,

[2] V. V. Härri, A.Schneuwly, Supercapacitors Revolutionize Energy Storages, proceedings EVS-17 (el. vehicle symposium), 2000,Montreal, www.hslu.ch/iiee

[3] V. V. Härri, S. Egger, Supercapacitor Circuitry Concept "SAM" for Public Transport Vehicles and other Applications, proceedings EVS-18 (el. vehicle symposium), 2001, Berlin www.hslu.ch/iiee

[4] V. V. Härri, P. Schweizer, H. J. Riesen, D. Carriero, P. Collins, Small bus TOHYCORider with Supercapacitor Storage SAM, final report of Swiss Federal Office of Energy SFOE, department mobility and energy storages, December 2008, www.hslu.ch/iiee

[5] D. Linzen, S. Buller, E. Karden and R.W. De Doncker, Analysis and Evaluation of Charge-Balancing-Circuits on Performance, Reliability, and Lifetime of Supercapacitor Systems, IEEE transactions on industry applications, vol. 41, no. 5, September/October 2005.

[6] V.Härri, S.Egger, S.Eigen, Industrietauglicher

Superkapazitätenspeicher SAM, Project KTI 4504.1 FHS of Swiss Federal Office for Professional Education and Technology OPET, January 2003: www.hslu.ch/iiee
[7] World Alliance for Decentralized Energy, http://www.localpower.org/deb_where.html

[8] J. G. Slootweg and W. L. Kling, Impacts of Distributed Generation on Power System Transient Stability, in Proc. 2002 IEEE Power Engineering Society Summer Meeting, vol 2, pp. 862-867.

[9] V.V.Härri, S.Egger, CC IIEE, HSLU T\&A Lucerne, All-Purpose Circuitry Concept SAM, Applications and Networking for Supercapacitors, Proceedings 2nd BoostcapMeeting 29.3.01, montena-components sa., $\mathrm{CH}-$ 1728 Rossens: www.hslu.ch/iiee

[10] P.Schweizer, V.Härri, Dezentrale Energiespeicherung im System Gebäude \& Mobilität, proceeding for "10. Symposium Energieinnovation", 13.-15.2.2008, Graz/Austria"

[11] Vinzenz V. Haerri, Drago Martinovic, Supercapacitor Module SAM for Hybrid Busses: an Advanced Energy Storage Specification based on Experiences with the TOHYCO-Rider Bus Project, Proceedings of the 2007 IEEE Conference IECON-07 in Taipei, Taiwan, November 2007

[12] U. Madawala, P. Schweizer, V. V. Haerri, Living and Mobility- A Novel Multipurpose inhouse Grid Interface with Plug in Hybrid BlueAngel, in Proc. 2008 IEEE Sustainable Energy Technologies Conference ICSET, Singapure, 24-27 Nov. 2008

[13] V. V. Haerri, U. Madawala, D. Zabkar, An Electric Micro-Scooter with a Supercapacitor Energy Buffer, in Proc. 2008 IEEE Sustainable Energy Technologies Conference ICSET, Singapure, 24-27 Nov. 2008

[14] P. Schweizer, V. V. Haerri, D. Zabkar, Testreport of Mitsubishi IMIEV, Lucerne University of Applied Sciences \& Arts, CH6048 Horw, www.hslu.ch/iiee

[15] P. Schweizer, V. V. Haerri, Living and Mobility - Vehicle to Grid with Light Weight Plug-In Hybrid Blue-Angel and Autago, International Advanced Mobility Forum IAMF, Motorshow Geneva, 2009-03-11, Lucerne University of Applied Sciences \& Arts, CH-6048 Horw, $\underline{\text { www.hslu.ch/iiee }}$ 


\section{Authors}

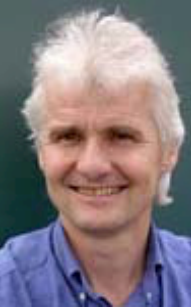

Prof. Vinzenz V. Härri graduated as electrical engineer at the Swiss Federal Institute of Technology Zurich in power electronics and drives. Working on industrial drives and locomotives at $\mathrm{BBC}$ and $\mathrm{ABB}$. Today working as a full-time lecturer at the Lucerne University of Applied Sciences and Arts. Head "Center of Competence IIEE Efficient Energy Systems".

Paul Schweizer graduated as electrical engineer at the Swiss Federal Institute of Technology Zurich in power electronics and drives. Activities on electrical and hybrid vehicles all over the world. CEO of PASOL AG in Switzerland. Research work at the Lucerne University of Applied Sciences and Arts (Center of Competence IIEE Efficient Energy Systems) 